\title{
CLASSIFICATION OF THE SEVERITY OF ACUTE SPINAL CORD INJURY: IMPLICATIONS FOR MANAGEMENT
}

\author{
By Michael B. Bracken, Ph.D., ${ }^{1}$ Samuel B. Webb, JR, DR P.H. ${ }^{1}$ \\ and FRANKLIN C. WAGNER, M.D. ${ }^{2}$ \\ ${ }^{1}$ Department of Epidemiology and Public Health; ${ }^{2}$ Division of Neurosurgery, Department of \\ Surgery; Yale University School of Medicine, 33 Cedar Street, New Haven, \\ Connecticut 06510, U.S.A.
}

Abstract. Sensory and motor function scales using a comprehensive neurological examination in emergency departments were developed during a 5-year prospective study of the epidemiology of acute spinal cord injury. Cross-classification of the scales on I 33 patients identified I 8.8 per cent who had severe motor impairment but minimal or no sensory loss. This discrepancy was not associated with older age or comorbidity but these patients tended to have a higher prevalence of fracture dislocations, hyperesthesia and Brown-Sequard Syndrome. The discrepancy between sensory and motor function was almost certainly due to the pathology of the cord lesion. Overall, motor function was more likely than sensory function to show improvement during the acute hospitalisation. This was especially true for patients admitted with good sensory but poor motor function. These patients need to be delineated soon after injury if we are to fully understand the aetiology of spinal cord injury and appropriately manage and evaluate different therapeutic modalities.

Key words: Classification; implications for management.

\section{Introduction}

WHILE the overall incidence of spinal cord injury appears to be low (Kraus et al., 1975), the physical, psychological, and economic implications for the individual patient remain calamitous. In order to identify factors which may influence the outcome of cord injuries, increasing interest has developed in large scale surveys and epidemiological studies largely supported by the National Institute of Neurological and Communicative Disorders and Stroke, and the Social and Rehabilitation Service of HEW. If these studies are to be meaningful, more precise classification schemes of spinal cord injury, which meet sometimes conflicting clinical and research requirements, must be developed. In this paper we report an approach to the problem of classifying spinal cord injured patients in terms of the severity of their sensory and motor status as determined shortly after injury and at discharge from the acute care hospital.

The more specifically the aetiology of acute spinal cord injury can be defined, the better our chances of intervention to reduce the frequency with which it occurs. Thus classifications of acute spinal cord injury, which are able to delineate injury due to automobile accidents and, more specifically, nature of the accident, speed of the autos, weather conditions, and seat belt usage, for example, will point the way to more precise social interventions for lowering incidence.

Unfortunately, the cause of acute spinal cord injury tells us little about the type of treatment the injury demands. The patient presenting with a complete lesion of the $\mathrm{C}_{5}$ cord segment, who is victim of an automobile accident, will not receive different treatment from the patient presenting with the same symptoms,

Address for reprints: Dr Bracken, Yale University School of Medicine. 
who was injured while diving. We believe, therefore, it is necessary to construct a classification of acute spinal cord injury which is related more precisely to the neurological deficit which the patient demonstrates shortly after sustaining injury and during subsequent treatment.

Classification schemes based on the forces which produced injury to the vertebral column have been developed (Roaf, I972). Though a useful concept, it is not always possible, in the clinical setting, to reconstructthe physical dynamics of the injury, nor is vertebral injury necessarily correlated with an injury to the spinal cord.

Other classification schemes reflect the extent of neurological deficit in terms of the loss of sensory and of motor function (Michaelis, I969; Jocheim, 1970; Cheshire, 1970). The virtue of this approach is that a principal goal of management is to maximise the patient's return of physical function. Unfortunately, such schemes frequently make use of vague criteria such as 'significant', 'greater or lesser', 'satisfactory or unsatisfactory', 'complete' and 'incomplete'. Such imprecise terms often fail to delineate neurological syndromes which require specific modes of management.

Additional problems common to most previous attempts at classification have included: variation in the time at which clinical testing occurs, which has ranged from within 24 hours of injury to 6 weeks later (Michaelis, I969); poor interobserver reliability; and delaying classification until after early therapy which precludes evaluation of the effect of subsequent management modalities.

\section{The Development of a Spinal Cord Injury Severity Classification}

In 1973 the Yale Spinal Cord Injury Study Group undertook a 5-year prospective investigation of the epidemiology of acute spinal cord injury. A methodology for identifying patients was designed with the cooperation of 26 acute general hospitals in Connecticut and 45 surgeons. Each week, new cases are identified through telephone contact with the hospitals and each neurosurgical office participating in the study. Detailed clinical, psychosocial and epidemiological information is obtained through personal interviews with the patient, physicians, hospital and ambulance personnel. The data collected include: type of care at injury site; care during transportation to the hospital and in the emergency department; methods of care and clinical evaluations during the first acute care hospitalisation. Measures of functional status and clinical evaluations are repeated at discharge from the acute care hospital and I year after injury.

The development of sensory and motor severity scales, described below, are derived from clinical evaluation data of acute spinal cord injured patients at the time of admission into the hospitals participating in the study. The same clinical evaluations were repeated in the week before discharge from the same hospitals, permitting an assessment of changes in sensory and motor function during the acute hospital stay. Of particular interest in this paper is the congruence between the sensory and motor severity measures. The analyses are based on the first I 33 cases in our series.

\section{Measurement of Sensory Level}

On the data collection instrument for collecting sensory level data designed for the study the clinician records bilaterally for each spinal cord segment whether sensory functioning is absent, decreased, or normal. In order to develop a complete clinical picture, the patient's response to five stimuli are measured. These are: superficial pain; light touch; position sense; vibratory sense; and deep pain. These 
procedures permit us to record, in graphic detail, the patient's functional sensory level.

While the data collection instrument provides a complete clinical picture of each patient's sensory function it remains necessary to construct a more tractable classification for research and patient management purposes. The patient's response to pinprick was used to develop this measure and the criteria used for ranking the severity of loss of sensory function are shown in Table I.

The four severest categories ( 7 through 4 ) are approximately equivalent to other classifications for quadriplegia, paraplegia, quadriparesis and paraparesis respectively. Response to stimuli has been measured using the more precise techniques of spinal cord segments rather than vertebral levels. Moreover, we have selected TI as the lowest involved cord segment for inclusion as quadriplegia or quadriparesia because of its significant representation in the upper extremity.

Category 3 on the severity scale includes cases observed to have a number of segments with absent sensory function but with a return to normal or decreased sensation in lower segments. Patients having segments with decreased sensations but normal sensation below are put in category 2. Normal sensation of all spinal cord segments is recorded in category $I$.

\section{Measurement of Motor Level}

To record motor level function the clinician records bilaterally for each appropriate myotome whether there is: no contraction; a flicker or some trace of contraction; active movement without antigravity; active movement with antigravity; or active movement against resistance. Readers will recognise the similarity between this measure and the British Medical Research Council's approach which is widely used in many centres (Michaelis, I969). For epidemiological studies data are taken from this clinical record and grouped into five levels of severity following the criteria shown in Table II. Category 5, the most severe, occurs when the most proximal myotome with absent contraction is the first palmar interosseus or higher. When the absence of contraction occurs in, or

TABLE I

Criteria used for sensory severity scale

\begin{tabular}{|c|c|c|c|c|c|c|}
\hline \multirow{3}{*}{$\begin{array}{l}\text { Sensory } \\
\text { severity } \\
\text { scale* }\end{array}$} & \multirow[t]{3}{*}{ Description } & \multicolumn{5}{|c|}{ Pain (pin prick) } \\
\hline & & \multicolumn{2}{|c|}{ Higher level $\dagger$} & \multirow[t]{2}{*}{ Absent } & \multicolumn{2}{|c|}{ Lower level } \\
\hline & & Normal & Decreased & & Decreased & Normal \\
\hline 7 & Quadraplegic & Yes & Yes & CI to TI & No & No \\
\hline 6 & Paraplegic & Yes & Yes & $\mathrm{T}_{2}$ to $\mathrm{S}_{5}$ & No & No \\
\hline 5 & Quadraparetic & Yes & CI to TI & No & Yes & No \\
\hline 4 & Paraparetic & Yes & $\mathrm{T}_{2}$ to $\mathrm{S}_{5}$ & No & Yes & No \\
\hline 3 & $\begin{array}{l}\text { Some segments } \\
\text { absent }\end{array}$ & Yes & Yes & Any level & Yes & Yes \\
\hline 2 & Some segments & & & & & \\
\hline I & decreased & Yes & Any level & No & No & Yes \\
\hline & Normal & res & $1 \mathrm{~N}$ & No & 100 & res \\
\hline
\end{tabular}

* See text for details. $†$ Levels based on spinal cord segments. 
TABLE II

Criteria used for motor severity scale

\begin{tabular}{|c|c|c|c|c|c|}
\hline \multirow{2}{*}{$\begin{array}{l}\text { Motor } \\
\text { severity } \\
\text { scale* }\end{array}$} & \multicolumn{2}{|c|}{ Higher level $\dagger$} & \multirow{2}{*}{$\begin{array}{c}\text { No } \\
\text { contraction }\end{array}$} & \multicolumn{2}{|c|}{ Lower level } \\
\hline & $\begin{array}{l}\text { Active antigravity } \\
\text { against resistance }\end{array}$ & $\begin{array}{c}\text { Flicker, trace } \\
\text { active antigravity }\end{array}$ & & $\begin{array}{c}\text { Flicker, trace } \\
\text { active antigravity }\end{array}$ & $\begin{array}{l}\text { Active antigravity } \\
\text { against resistance }\end{array}$ \\
\hline 5 & Yes & Yes & $\mathrm{C}_{5} \rightarrow \mathrm{T}_{\mathrm{I}}$ & No & No \\
\hline 4 & Yes & Yes & $\mathrm{L}_{\mathrm{I}} \rightarrow \mathrm{S}_{2}$ & No & No \\
\hline 3 & Yes & $\mathrm{C}_{5} \rightarrow \mathrm{T}_{\mathrm{I}}$ & No & Yes & No \\
\hline 2 & Yes & $\mathrm{L} I \rightarrow \mathrm{S}_{2}$ & No & Yes & No \\
\hline $\mathrm{I}$ & $\mathrm{C}_{5} \rightarrow \mathrm{T}_{\mathrm{I}}$ & No & No & No & Yes \\
\hline
\end{tabular}

* See text for details. † Levels based on spinal cord segments.

below, the ilio-psoas patients are placed in category 4. Categories 3 and 2, respectively, are used when a trace of a contraction is exhibited in some muscles of a myotome. The lowest category delineates patients having at least active movement against gravity in all myotomes.

The inclusion of patients scoring 'normal' on the sensory and motor severity tests requires further explanation. These patients present an overall clinical picture which is consistent with transient cord injury even though their sensory and motor test results are normal. Among the signs exhibited by these patients are: the Babinski reflex syndrome; one or more absent or decreased reflexes; and patient complaints of weakness or numbness in an extremity. These patients are often overlooked in epidemiological studies of acute spinal cord injury. Moreover, a failure to consider these patients as having spinal cord injury is likely to lead to serious error in patient management.

\section{Correlation of the Sensory and Motor Severity Scales}

In Table III we show the cross-tabulation of the sensory and motor severity scales on the series of I 33 patients.

\section{TABLE III}

Cross-classification of sensory and motor scales

\begin{tabular}{|c|c|c|c|c|c|c|c|c|c|}
\hline \multirow[t]{2}{*}{ Motor scale } & \multicolumn{7}{|c|}{ Sensory scale } & \multicolumn{2}{|c|}{ Total } \\
\hline & 7 & 6 & 5 & 4 & 3 & 2 & I & $n$ & $\%$ \\
\hline 5 & 37 & 4 & 4 & 0 & 2 & 5 & 2 & 54 & $40 \cdot 6$ \\
\hline 4 & 5 & I8 & I & 5 & I & I & 2 & 33 & $24 \cdot 8$ \\
\hline 3 & I & I & 2 & I & 2 & 4 & 6 & I7 & I2.8 \\
\hline 2 & 0 & 0 & 0 & 2 & 0 & 3 & 2 & 7 & $5 \cdot 3$ \\
\hline I & 0 & I & 2 & I & 0 & 4 & I4 & 22 & $16 \cdot 5$ \\
\hline $\begin{array}{l}\text { Total } \\
n \\
\%\end{array}$ & $\begin{array}{r}43 \\
32 \cdot 3\end{array}$ & $\begin{array}{r}24 \\
18.0\end{array}$ & $\begin{array}{r}9 \\
6.8\end{array}$ & $\begin{array}{r}9 \\
6.8\end{array}$ & $\begin{array}{r}5 \\
3 \cdot 8\end{array}$ & $\begin{array}{r}17 \\
12 \cdot 8\end{array}$ & $\begin{array}{r}26 \\
19.5\end{array}$ & I33 & $100 \cdot 0$ \\
\hline
\end{tabular}

Tau $c=0.58 . \quad \mathrm{P}<0.000 \mathrm{I}$. 
Looking at the frequency for the total sensory severity scale we see that exactly one-third of the sample are in the most severely deprived sensory group. The most severe motor level contains 40.6 per cent of the total sample. Observation of the cells in the table shows, as we would expect, a fairly strong correlation between the two scales (tau $c=0.58, \mathrm{P}<0.00 \mathrm{I}$ ). Nonetheless, a substantial number of cases show some discrepancy between the two measures. Moreover, the majority of these are cases where severe motor dysfunction is associated with relatively less severe sensory impairment. The data show, then, that if loss of sensory function is severe, motor function is almost certainly also poor. However, if motor function is poor, sensory function may be maintained. Indeed seven patients showed the most severe loss of motor function (motor category 5) but minimal, or no loss of sensory function (sensory categories 2 and I).

The patient ages were examined because of the possibility that older patients were exhibiting poor motor function even though their sensory function was relatively normal. For this comparison the 25 cases in sensory categories 3, 2 and I and motor categories 5, 4 and 3, the most discrepant group, were examined. On average the discrepant group was 5 years younger than the rest of the sample (30.2 v. 35.5 years respectively, $t=0.94, \mathrm{~ns})$; more specifically, two patients were over the age of $60 \mathrm{v}$. eight patients over 60 years old in the rest of the sample.

Secondly, we looked at the data to see if loss of motor but not sensory function resulted from comorbidity such as an accompanying head injury. Both the discrepant group and the remainder of the sample showed the same, low rates of associated injuries. Thus older age or comorbidity did not appear to account for the observed discrepancies between sensory and motor function.

Third, we looked at the prevalence of associated fractures and dislocations in the two groups. Only one patient in the group with poor motor, but relatively superior sensory, function did not have a fracture or dislocation (or both) whereas I2 of 74 in the remainder of the sample who had X-rays had no fracture or dislocation.

In the total sample there were five cases with hyperesthesia although two of them occurred in the discrepant group. In addition, a total of four cases had Brown-Sequard Syndrome and two of these were in the group with large sensory and motor function discrepancies.

\section{Changes in Sensory and Motor Function During Acute Hospital Stay}

By repeating the sensory and motor function evaluations during the course of treatment we are able to assess the efficacy of different management manoeuvres. The classification scheme not only indicates whether or not there has been a change in function but the degree of change. Function 'change scores' are computed simply by subtracting the score at discharge from that taken in the emergency room. Thus a zero score indicates no change, a negative score a change for the worse and a positive score shows improvement. The larger score indicates greater change.

Table IV shows the results of classifying the patients in our series in this manner. Here we report changes in sensory and motor function between admission and discharge from the acute care hospital. For both sensory and motor evaluations, approximately two-thirds of the patients remained unchanged. Deterioration occurred twice as frequently in sensory than motor function (1 4.6 per cent $v$. 7.8 per cent respectively) and improvement in function was correspondingly less for sensory than motor function (22.I per cent versus $30 \cdot 8$ per cent respectively). 
TABLE IV

Change in sensory and motor function from admission to discharge

\begin{tabular}{|c|c|c|c|c|c|}
\hline \multicolumn{3}{|c|}{ Sensory function } & \multicolumn{3}{|c|}{ Motor function } \\
\hline $\begin{array}{l}\text { Change } \\
\text { score* }\end{array}$ & $n$ & $\%$ & $\begin{array}{c}\text { Change } \\
\text { score } \dagger\end{array}$ & $n$ & $\%$ \\
\hline-5 & I & 0.9 & - & - & - \\
\hline-4 & I & 0.9 & - & - & - \\
\hline-3 & 4 & $3 \cdot 7$ & -3 & I & 0.9 \\
\hline-2 & 8 & $7 \cdot 3$ & -2 & 3 & $2 \cdot 6$ \\
\hline$-I$ & 2 & $\mathrm{I} \cdot 8$ & $-I$ & 5 & $4 \cdot 3$ \\
\hline 0 & 69 & $63 \cdot 3$ & 0 & 72 & $61 \cdot 5$ \\
\hline I & 13 & I I 9 & I & 8 & 6.8 \\
\hline 2 & 4 & $3 \cdot 7$ & 2 & 23 & 19.7 \\
\hline 3 & 3 & $2 \cdot 8$ & 3 & 4 & $3 \cdot 4$ \\
\hline 4 & 3 & $2 \cdot 8$ & 4 & I & 0.9 \\
\hline 6 & I & 0.9 & - & - & - \\
\hline Total & 109 & $100 \cdot 0$ & & II 7 & $100 \cdot 0$ \\
\hline
\end{tabular}

* Changes in sensory function may range from -6 to +6 . A zero indicates no change; a negative score indicates decreased function and a positive score indicates increased function. Larger numbers reflect greater change.

$\dagger$ Change in motor function is scored as for sensory function change except that the change score may range from -4 to +4 .

It is of particular interest to note the majority of patients, as we might expect, show quite modest changes in function, others show a considerable amount of change.

Finally, it was of interest to note that at discharge the correlation between sensory and motor function was higher ( $\operatorname{tau} c=0.73, \mathrm{P}<0.001)$ than it had been in the emergency room. This was principally due to improvement in motor function during the hospital stay among patients in the discrepant group who in the emergency room had good sensory but poor motor function.

\section{SUMMARY AND DISCUSSION}

Before discussing the study findings it is necessary to review some shortcomings of the motor and sensory severity scales presented above. Assessment of severity is still not entirely objective. The clinician is asked to differentiate between absent, decreased, and normal sensation. Nonetheless, we believe future studies will show a high degree of reliability in these estimates when made by different clinicians. Of course, even with the advent of more advanced technological techniques, estimates of severity will never be entirely devoid of human variation in recording sensory and motor function.

A second problem is that clinicians are reluctant to complete all sensory tests using the five stimuli especially when testing is performed in the emergency room. Schneider, et al. (1973), have previously criticised the apparent trend to rush patients into surgery while neglecting to perform 'a time-consuming and careful 
evaluation of the neurological status. The increasing interest in the discrepancy between motor and sensory function and the implications this has for management further point out the need for a detailed assessment of the patient's status.

Using the scales developed for our epidemiological study we have observed considerable discrepancy between severity of motor and sensory impairment. The discrepant group is almost entirely composed of the patients who have greater motor, $v$. sensory, loss. Indeed, I 8.8 per cent of the sample had severe motor loss with very little or no sensory impairment; findings which could not be ascribed to age or comorbidity. It is more likely that these discrepancies are explicable in anatomical terms. As we might expect, Brown-Sequard Syndrome was more prevalent in the discrepant group. Interestingly, however, fracture and dislocation was also more common in the discrepant group as was hyperesthesia Possibly fracture dislocations are associated with root involvement which, in turn, is correlated with hyperesthesia. In addition, we would expect the discrepant group to contain patients with a variety of spinal cord syndromes including: acute anterior spinal cord injury syndrome; acute central cervical spinal cord syndrome; cruciate paralysis of Bell; and bilateral brachial plexus injury. These have all been described in more detail by other investigators (Guttman, I973; Schneider et al., 1973). At this stage our data do not provide the clinical details necessary to confirm these suspicions.

Irrespective of clinical diagnosis, the ability of our classification scheme to identify patients who have some discrepancy between sensory and motor severity has important implications for clinical, psychosocial and epidemiological studies of acute spinal cord injury. Traditionally these patients have been classified as quadriplegics or paraplegics, and approach posing problems in at least three areas. First, unless we separate out these syndromes, from other forms of injury, in large data sets we will not understand the epidemiology or aetiology of them. Moreover, our understanding of more classical forms of acute spinal cord injury will also be diminished. Second, these patients demand special therapeutic interventions which, in turn, require continuing evaluation and refinement. Clearly, this first requires suitable classification of the syndrome. Third, in order to assess the full range of management techniques required of spinal cord injury we no longer can rely entirely on simplistic classifications. Other investigators continue to report difficulty evaluating treatment in the absence of complete documentation of sensory and motor function (Heider et al., 1975). Furthermore, the social and institutional resources brought to bear on acute spinal cord injury can only be accurately assessed using more specific injury classification.

All who work with acute cord injured patients are aware of our inability to predict accurately, even among patients with similar injury, those who will experience optimal functional outcome. More exact specification of the injury will help us explain some additional variation in patient response to our clinical interventions.

\section{RÉSUMÉ}

Les mesurements des fonctions sensorielles et moteures, employant une inspection neurologique compréhensive dans les départements des services de secours, on été développés pendant une évaluation prospective de cinq (5) ans de l'épidémiologie d'une injure aiguë de la corde épinale. Une classification croisée de ces mesurements de 133 malades a identifié $18.8 \%$ qui avaient un affaiblissement moteur sévère et très peu ou aucune perte des fonctions sensorielles. Ce désaccord n'était pas associé avec un âge avancé ou avec la commorbidité, mais ces malades avaient le penchant vers une prédominance de dislocations avec fractures, d'hyperesthésies, et du syndrome de Brown-Séquard. Le désaccord entre 
la fonction sensorielle et la fonction moteure était presque certainment causé par la pathologie de la lésion de la corde épinale. En général, la fonction moteure plutôt que la function sensorielle semblait plus probable de sáméliorer pendant l'admission a hôpital durant la période aiguë. Ceci était surtout vrai avec les malades admis avec une bonne fonction sensorielle mais une fonction moteure deteriorée. Ces malades doivent être examinés tout de suite après une injure de la corde épinale si nous voulons complétement comprendre l'étiologie de cette injure et donner le propre traitement ainsi qu'évaluer les différentes modalitiées thérapeutiques.

\section{ZUSAMMENFASSUNG}

Während einer fünf-jährigen, geplanten Studie der Epidemiologie von akuten Rückenmark-Verletzungen wurden sensible und motorische Funktionsausschläge durch eine umfassende neurologische Prüfung in Nothilfestationen entwickelt. Kreuzweise Einstufung einer Skala von 133 Patienten liess $18.8 \%$ mit ernstlichen, motorischen Beeinträchtigungen, aber minimalen oder gar keinen sensiblen Verlusten erkennen. Dieser Widerspruch bezog sich weder auf höheres Alter noch auf eine vorausgegangene Erkrankung, sondern diese Patienten neigten dazu, häufigere Brüche und Verrenkungen, sowie Überempfindlichkeit und Brown-Sequard Syndrom zu haben. Der Unterschied zwischen sensiblen und motorischen Funktionen bezog sich fast ausschliesslich auf the Pathologie von Rückenmark-Verletzungen.

Zusammenfassend wurde beobachtet, dass sich motorische Funktionen durch sofortige Hospital-Aufnahame eher besserten als sensible Funktionen. Diese Beobachtung bestätigte sich vor allem in Patienten mit guten sensiblen, aber schwachen motorischen Funktionen. Solche Patienten benötigen, so schnell als möglich nach einer Verletzung erkannt zu werden, wenn wir die Etiologie der Rückenmark-Verletzung die zuständige Handhabung, sowie Erwägung verschiedener Behandlungsweisen völlig zu verstehen hoffen.

Acknowledgments. We wish to thank Cheryl Austein, M.P.H.; Evarist Berzins, M.P.H.; M. Elizabeth Lorenzi, B.A. and Mary Jo Shepard, M.P.H. for their assistance in data collection and analysis. The study is supported, in part, by the National Institute of Neurological and Communicative Disorders and Stroke (NS No. IOI74).

\section{REFERENCES}

Cheshire, D. J. E. (1970). A classification of the functional end-results of injury to the cervical spinal cord. Paraplegia, 8, 70.

Guttmann, L. (1973). Spinal Cord Injuries, Comprehensive Management and Research. Blackwell, Oxford.

Heider, J. S., Weiss, M. H., Rosenberg, A. W. et al. (1975). Management of cervical spinal cord trauma in Southern California. Fournal of Neurosurgery, 43, 732.

JochHeIM, K. A. (I970). Problems of classification in traumatic paraplegia and tetraplegia. Paraplegia, 8, 80.

KRAUS, J. F., FrANTI, C. E., Riggins, R. S. et al. (1975). Incidence of traumatic spinal cord lesions. Fournal of Chronic Disease, 28, 47I.

MichaELIS, L. S. (I969). International inquiry on neurological terminology and prognosis in paraplegia and tetraplegia. Paraplegia, $7, \mathrm{I}$.

RoAf, R. (I972). International classification of spinal injuries. Paraplegia, Io, 78.

SCHNEInER, R. C., Crosby, E. C., Russo, R. H. \& GosCH, H. H. (I973). Traumatic spinal cord syndromes and their management, Chapter 32, Clinical Neurosurgery, 20. 